\title{
Frequency of Benign and Malignant Tumors in Localized Vitiligo in Comparison to Generalized and Universal Vitiligo
}

\author{
Khalifa E. Sharquie ${ }^{1,2^{*}}$, Adil A. Noaimi ${ }^{1,2}$, Sadiq J. Murtada ${ }^{3}$ \\ ${ }^{1}$ Department of Dermatology, College of Medicine, University of Baghdad, Baghdad, Iraq \\ ${ }^{2}$ Iraqi and Arab Board for Dermatology and Venereology, Baghdad Teaching Hospital, Medical City, Baghdad, Iraq \\ ${ }^{3}$ Department of Dermatology, Baghdad Teaching Hospital, Medical City, Baghdad, Iraq \\ Email: *ksharquie@ymail.com, adilnoaimi@yahoo.com, sadiqjafar1976@yahoo.com
}

Received 3 May 2016; accepted 1 August 2016; published 4 August 2016

Copyright (C) 2016 by authors and Scientific Research Publishing Inc.

This work is licensed under the Creative Commons Attribution International License (CC BY).

http://creativecommons.org/licenses/by/4.0/

(c) () Op Open Access

\section{Abstract}

Background: Autoimmune diseases like pemphigus and systemic lupus erythematosus are protective against skin malignancies like basal cell carcinoma and squamous cell carcinoma. Objective: As vitiligo is an autoimmune diseases, the aim of the present work is to record the frequency of all benign and malignant skin tumors among patients with different severity of vitiligo and to be compared with the skin tumors in healthy control. Patients and Methods: This is a case series, descriptive study done in the Department of Dermatology-Baghdad Teaching Hospital, Baghdad, Iraq, during the period from May 2014-May 2015. History was taken from each patient with vitiligo regarding age, gender, duration, personal and family history of vitiligo and other autoimmune diseases such as diabetes mellitus, thyroid dysfunction, and alopecia areata. Patients were assessed for past and present history of photodermatosis and any skin cancers. Healthy control was considered. Results: Three hundred and fifty patients with vitiligo were included in this study: 50 patients with universal vitiligo, 100 patients with generalized vitiligo, and 200 patients with localized vitiligo as well as $\mathbf{5 0 0}$ subjects as a healthy control. The ages of all studied subjects ranged between 31 and 77 years. Twenty four(48\%) patients with universal vitiligo were males and 26 $(52 \%)$ were females; $49(49 \%)$ patients with generalized vitiligo were males and $51(51 \%)$ were females; $101(50.5 \%)$ patients with localized vitiligo were males and $99(49.5 \%)$ were females and 235(47\%) of control were males and $265(53 \%)$ were females. All skin tumors were seen to be high in healthy subjects and lower or absent in patients with vitiligo. Also patients with mild vitiligo had a higher frequency of skin tumors including benign and malignant than patients with severe vitiligo especially in patients with universal vitiligo. In addition, no photosensitivity or actinic reticuloid was detected in patients with vitiligo. Conclusions: Vitiligo especially generalized and universal type as an autoimmune disease had a protective action against photodamage, photosen-

${ }^{*}$ Corresponding author.

How to cite this paper: Sharquie, K.E., Noaimi, A.A. and Murtada, S.J. (2016) Frequency of Benign and Malignant Tumors in Localized Vitiligo in Comparison to Generalized and Universal Vitiligo. Journal of Cosmetics, Dermatological Sciences and Applications, 6, 133-139. http://dx.doi.org/10.4236/jcdsa.2016.64017 
sitivity and skin tumors whether benign or malignant.

Keywords

Vitiligo, Photodamage, Photoprotection, Benign and Malignant Tumors

\section{Introduction}

Skin tumors, commonly basal cell carcinoma, squamous cell carcinoma and malignant melanoma are common dermatological diseases that are encountered in daily clinical practice. They are diseases of middle age but might occur in young people where genetic factors are involved in their pathogenesis which makes these people more tendency to have sunlight damage and skin malignancies [1] [2]. As prolonged sunlight exposure is greatly incriminated in basal cell carcinoma, squamous cell carcinoma and malignant melanoma, some people are strongly liable to have these diseases like xeroderma pigmentosa, xerodermoid, albinism, epidermodysplasia veruciformis [3] [4], immunosuppressed disorders like kidney transplant patient [5]. From daily clinical practice, we have noticed that many patients with autoimmune disease had lower frequency of infections and skin tumors. Sharquie et al. had confirmed this hypothesis especially in relation to pemphigus vulgaris and systemic lupus erythematosus and the results were very encouraging [6]. These results encouraged to conduct a study in patients with vitiligo where it was found that patients with vitiligo had lower frequency of malignancy and this was attributed to high P53 in lesional and perilesional skin compared to normal skin [7]. These interesting findings are the basis of the present work aiming to record different skin tumors in patient with vitiligo in their different severities including mild (localized), wide spread (generalized) and severe (universal) vitiligo.

\section{Patients and Methods}

This a case series, descriptive comparative study carried out in the Department of Dermatology-Baghdad Teaching Hospital, Baghdad, Iraq during the period from May 2014-May 2015. Formal consent was taken from each patient after full explanation about the goal and nature of the present work. Also, ethical approval was taken from the Scientific Council of Dermatology and Venereology-Iraqi Board for Medical Specializations.

Patients with vitiligo were aged 30 years or older at the time of the study, participate to record any association of skin malignancies in 350 vitiligo patients ( 200 with localized vitiligo, 100 with generalized vitiligo and 50 with universal vitiligo) and to be compared with 500 approved healthy individuals as a control group.

History was taken from each patient regarding: age, gender, duration, family history of vitiligo and history of other autoimmune diseases such as diabetes mellitus, thyroid dysfunction, alopecia areata and others, phototherapy history, and any skin tumors experienced during the patient's lifetime. The diagnosis was clinically done with the aid of Wood's light examination if needed. All patients with vitiligo are photographed by Apple Ipad 4 Wi-Fi combines 5 megapixel camera in same place, distance and illumination. Also, dermatological study was carried out to categorize the types of vitiligo and to detect any associated nevi. The severity of depigmentation in patient with vitiligo was assessed as follow:

$$
\begin{array}{ll}
1 \%-25 \% & \text { Mild. } \\
>25 \%-50 \% & \text { Moderate. } \\
>50 \%-75 \% & \text { Severe. } \\
>75 \% & \text { Universal. }
\end{array}
$$

In the present study the distribution of depigmentation was classified as follow:

$1 \%-25 \% \quad$ Localized.

$>25 \%-75 \%$ Generalized.

$>75 \% \quad$ Universal.

Statistical Analysis of data was carried out using the statistical package of SPSS-20 (Statistical Packages for Social Sciences-version 20). Data were presented in simple measures of frequency, percentage, mean and standard deviation. Comparison between groups was done by using Chi Square, Fisher exact test, T-test and ANOVA test, $\mathrm{p}$-value $<0.05$ was considered as the level of significance. 


\section{Results}

\section{Demographic and Descriptive Data}

Three hundred and fifty patients with vitiligo were included in the study (50 patients with universal vitiligo; 100 patients with generalized vitiligo; and 200 patients with localized vitiligo) as well as 500 approved healthy individuals as a control group.

All vitiligo patients and healthy control subjects had long time of outdoor activities as they live in very sunny country like Iraq.

The ages of all studied subjects ranged between $31-77$ years with a mean \pm SD of $43.42 \pm 10.22$ years. The ages of control ranged between $31-70$ years with a mean \pm SD of $42.85 \pm 9.78$ years, the ages of localized vitiligo ranged between $31-77$ years with a mean \pm SD of $43.85 \pm 11.34$ years, for those with generalized vitiligo, the age ranged between $31-75$ years with a mean \pm SD of $44.45 \pm 10.55$ years and for the universal vitiligo ranged between $31-65$ years with a mean \pm SD of $45.40 \pm 8.80$ years. All studied subjects were statistically matched regarding the age ( $\mathrm{p}$ value $=0.67$ ) as well as all three groups of vitiligo were statistically matched regarding the age ( $\mathrm{p}$ value $=0.64)$.

The duration of vitiligo in all 350 patients ranged between 3 - 55 years with a mean \pm SD of $22.10 \pm 8.66$ years. The duration of vitiligo in patients with localized vitiligo ranged between $4-36$ years with a mean \pm SD of $21.68 \pm 6.64$ years. While those with generalized vitiligo, the duration ranged between $3-55$ years with a mean \pm SD of $21.56 \pm 10.55$ years and for universal vitiligo ranged between $3-45$ years with a mean \pm SD of $24.86 \pm 10.87$ years. All patients were statistically matched regarding the duration of vitiligo ( $p$ value $=0.051$ ).

Twenty four (48\%) patients with universal vitiligo were males and $26(52 \%)$ were females, $49(49 \%)$ patients with generalized vitiligo were males and $51(51 \%)$ were females, $101(50.5 \%)$ patients with localized vitiligo were males and $99(49.5 \%)$ were females and $235(47 \%)$ of control were males and $265(53 \%)$ were females. All groups were statistically matched regarding gender ( $\mathrm{p}$ value $=0.865$ ) as well as all groups of vitiligo were statistically matched $(\mathrm{p}$ value $=938)$.

Family history of vitiligo was positive in $17(4.9 \%)$ patients, $6(3 \%)$ patients with localized vitiligo, $7(7 \%)$ with generalized vitiligo and $4(8 \%)$ with universal vitiligo had positive family history. Family history of vitiligo was not related to the type of vitiligo ( $\mathrm{p}$ value $=0.169$ ). Family history of vitiligo in control was recorded in 16 subjects $(3.2 \%)$ and there is no significant difference between control and vitiligo patients ( $\mathrm{p}$ value $=0.116$ ).

History of alopecia areata was positive in $13(3.7 \%)$ patients: $4(2 \%)$ patients with localized vitiligo, $7(7 \%)$ with generalized vitiligo and $2(4 \%)$ with universal vitiligo had history of alopecia areata. History of alopecia areata was not related to the type of vitiligo ( $\mathrm{p}$ value $=0.097$ ). History of alopecia areata in control was recorded in $14(2.8 \%)$ subjects and there is no significant difference between control and vitiligo patients ( $\mathrm{p}$ value $=$ 0.112 ).

History of diabetes mellitus was positive in $16(4.6 \%)$ patients: $5(2.5 \%)$ patients with localized vitiligo, $7(7 \%)$ with generalized vitiligo and $4(8 \%)$ with universal vitiligo had history of diabetes mellitus. History of diabetes mellitus was not related to the type of vitiligo ( $\mathrm{p}$ value $=0.097$ ). History of diabetes mellitus in control was recorded in 14 subjects $(2.8 \%)$ and there is no significant difference between controls and vitiligo patients ( $\mathrm{p}$ value $=0.065)$ (Table 1).

Table 1. The frequency of associated diseases in patients with vitiligo groups.

\begin{tabular}{|c|c|c|c|c|c|c|c|}
\hline & & \multicolumn{2}{|c|}{ Family history } & \multicolumn{2}{|c|}{ Alopecia areata } & \multicolumn{2}{|c|}{ Diabetes mellitus } \\
\hline & & $\mathrm{N}$ & $\%$ & $\mathrm{~N}$ & $\%$ & $\mathrm{~N}$ & $\%$ \\
\hline \multirow{3}{*}{$\begin{array}{l}\text { Vitiligo patients } \\
\qquad(\mathrm{n}=350)\end{array}$} & Localized Vitiligo & 6 & 3.0 & 4 & 2.0 & 5 & 2.5 \\
\hline & Generalized Vitiligo & 7 & 7.0 & 7 & 7.0 & 7 & 7.0 \\
\hline & Universal Vitiligo & 4 & 8.0 & 2 & 4.0 & 4 & 8.0 \\
\hline \multicolumn{2}{|c|}{ Control $(\mathrm{n}=500)$} & 16 & 3.2 & 14 & 2.8 & 15 & 3 \\
\hline \multicolumn{2}{|c|}{${ }^{*} \mathrm{p}$ value } & \multicolumn{2}{|c|}{0.169} & \multicolumn{2}{|c|}{0.097} & \multicolumn{2}{|c|}{0.097} \\
\hline \multicolumn{2}{|c|}{${ }^{* *} \mathrm{p}$ value } & \multicolumn{2}{|c|}{0.116} & \multicolumn{2}{|c|}{0.112} & \multicolumn{2}{|c|}{0.065} \\
\hline
\end{tabular}

${ }^{*}$ Chi square between all groups of vitiligo. ${ }^{* *}$ Chi square between groups of vitiligo and controls. 


\section{- Distribution of benign and malignant diseases:}

Seventy (14\%) of control had warts in comparison with $18(5.1 \%)$ patients with vitiligo. The percentage of warts was significantly affected by vitiligo ( $p$ value $=0.001$ ). Among patients with vitiligo; percentage of warts was more common in localized type $16(8 \%)$ patients in comparison with generalized type $2(2 \%)$ and no one with universal type had wart ( $\mathrm{p}$ value $=0.018)($ Table 2 , Table 3$)$.

Skin tags was presented in 64(12.8\%) of control and 36(10.3\%) patients with vitiligo and was statistically not significant ( $\mathrm{p}$ value $=0.263$ ). Incidence of skin tags was affected by type of vitiligo as $32(16 \%)$ patients with localized vitiligo had skin tags, $3(3 \%)$ patients with generalized type and $1(2 \%)$ patient with universal vitiligo (p value $=0.001)($ Table 2 , Table 3$)$.

Freckles and Lentigens were more common among controls than patients with vitiligo and were statistically significant ( $\mathrm{p}$ value 0.001 for each one). Thirty patients $(6 \%)$ of controls had freckles in comparison with one

Table 2. Frequency of benign and malignant diseases in controls and vitiligo patients.

\begin{tabular}{|c|c|c|c|c|c|}
\hline & \multicolumn{2}{|c|}{ Control (500 cases) } & \multicolumn{2}{|c|}{ Vitiligo ( 350 patients) } & \multirow{2}{*}{ "p value } \\
\hline & $\mathbf{N}$ & $\%$ & $\mathbf{N}$ & $\%$ & \\
\hline Warts & 70 & 14.0 & 18 & 5.1 & 0.001 \\
\hline Skin Tags & 64 & 12.8 & 36 & 10.3 & 0.263 \\
\hline Freckles & 30 & 6 & 1 & 0.3 & ${ }^{* *} 0.001$ \\
\hline Lentigens & 37 & 7.4 & 5 & 1.4 & 0.001 \\
\hline Melanocytic Nevi & 35 & 7.0 & 26 & 7.4 & 0.812 \\
\hline Actinic Keratosis & 21 & 4.2 & 5 & 1.4 & 0.021 \\
\hline Seborrheic Keratosis & 20 & 4.0 & 1 & 0.3 & ${ }^{* *} 0.001$ \\
\hline Epidermoid Cyst & 19 & 3.8 & 5 & 1.4 & 0.040 \\
\hline Porokeratosis & 3 & 0.6 & 0 & 0.0 & ${ }^{* *} 0.20$ \\
\hline Senile Comedon & 18 & 3.6 & 3 & 0.9 & ${ }^{* *} 0.012$ \\
\hline BCC & 6 & 1.2 & 0 & 0.0 & $* 0.046$ \\
\hline SCC & 5 & 1.0 & 0 & 0.0 & ${ }^{* *} 0.081$ \\
\hline KA & 3 & 0.6 & 0 & 0.0 & ${ }^{* *} 0.20$ \\
\hline
\end{tabular}

${ }^{*}$ Chi square; ${ }^{* *}$ Fisher exact test.

Table 3. The frequency of benign and malignant diseases in patients with different severity of vitiligo.

\begin{tabular}{cccccccc} 
& \multicolumn{2}{c}{ Localized Vitiligo (200) } & \multicolumn{2}{c}{ Generalized Vitiligo (100) } & \multicolumn{2}{c}{ Universal Vitiligo (50) } & * \\
\cline { 2 - 6 } & $\mathbf{N}$ & $\mathbf{\%}$ & $\mathbf{N}$ & $\mathbf{\%}$ & $\mathbf{N}$ & $\mathbf{\%}$ & 0.018 \\
Warts & 16 & 8.0 & 2 & 2.0 & 0 & 0.0 & 0.001 \\
Skin Tags & 32 & 16.0 & 3 & 3.0 & 1 & 2.0 & 0.0 \\
Freckles & 1 & 0.5 & 0 & 0.0 & 0 & 0.0 & 0.149 \\
Lentigens & 5 & 2.5 & 0 & 0.0 & 0 & 0.0 & 0.003 \\
Melanocytic Nevi & 23 & 11.5 & 3 & 3.0 & 0 & 0.0 & 0.517 \\
Actinic Keratosis & 4 & 2.0 & 1 & 1.0 & 0 & 0.0 & 0.0 \\
Seborrheic Keratosis & 1 & 0.5 & 0 & 0.0 & 0 & 0.0 & 0.087 \\
Epidermoid Cyst & 4 & 2.0 & 1 & 1.0 & 0 & 0.0 & 0.517 \\
Porokeratosis & 0 & 0.0 & 0 & 0.0 & 0 & 0.0 & 0.00 \\
Senile Comedon & 3 & 0.9 & 0 & 0.0 & 0 & 0.0 & 0.069 \\
BCC & 0 & 0.0 & 0 & 0.0 & 0 & 0.0 & 0.00 \\
SCC & 0 & 0.0 & 0 & 0.0 & 0 & 0.0 & 0.00 \\
KA & 0 & 0.0 & 0 & 0.0 & 0 & 0.0 & 0.00 \\
\hline
\end{tabular}

\footnotetext{
${ }^{*}$ Chi square.
} 
case of vitiligo $(0.3 \%)$ and $37(7.4 \%)$ of controls had lentigens in comparison with 5 cases of vitiligo (1.4\%). Freckles were presented only in localized type of vitiligo and were statistically not significant $(0.687)$ as well as lentigens presented in localized type of vitiligo and was statistically not significant (0.149) (Table 2, Table 3).

Melanocytic nevi were presented in 35(7\%) cases of controls and in $26(7.4 \%)$ patients with vitiligo and was statistically not significant ( $\mathrm{p}$ value $=0.812$ ). Among patients with vitiligo, incidence of melanocytic nevi was more common in localized type $23(11.5 \%)$ patients in comparison with generalized type 3(3\%) patients and no one with universal type had melanocytic nevi and was statistically significant( $\mathrm{p}$ value $=0.003$ ) (Table 2 , Table 3).

Actinic keratosis was presented higher in controls which are statistically significant ( $\mathrm{p}$ value $=0.021$ ). Twenty one subjects (4.2\%) of controls and 5(1.4\%) patients with vitiligo had actinic keratosis. Four (2\%) cases of actinic keratosis presented in patients with localized vitiligo and one (1\%) case in generalized type and was statistically not significant $(\mathrm{p}$ value $=0.517)($ Table 2 , Table 3$)$.

Seborrheic keratosis was presented in 20(4\%) cases of control and $1(0.3 \%)$ patients with vitiligo and was statistically significant $(\mathrm{p}$ value $=0.001)$. Seborrheic keratosis was presented in localized vitiligo only but statistically not significant $(\mathrm{p}$ value $=0.687)$ (Table 2 , Table 3$)$.

Epidermoid cyst was presented higher in controls and was statistically significant ( $\mathrm{p}$ value $=0.040$ ). Nineteen (3.8\%) subjects of controls and 5(1.4\%) patients with vitiligo had epidermoid cyst. Among patients with vitiligo, incidence of epidermoid cyst was more common in localized type 4(2\%) patients in comparison with generalized type $1(1 \%)$ patient and no one with universal type had epidermoid cyst and was statistically not significant $(\mathrm{p}$ value $=0.517)$ (Table 2 , Table 3$)$.

Three $(0.6 \%)$ subjects of control had porokeratosis in comparison to vitiligo group no one had porokeratosis, It was statistically not significant ( $\mathrm{p}$ value $=0.20$ ).

Senile comedon were presented in $18(3.6 \%)$ cases of controls and in 3(0.9\%) patients with vitiligo and was statistically significant $(\mathrm{p}$ value $=0.012$ ). All cases of senile comedon presented in patients with localized vitiligo $(\mathrm{p}$ value $=0.069)($ Table 2 , Table 3$)$.

BCC, SCC and KA presented only in controls and only BCC was statistically significant ( $\mathrm{p}$ value $=0.046$, 0.081 , and 0.20 respectively). $6(1.2 \%)$ of control had BCC, five $(1.0 \%)$ of control had SCC, three $(0.6 \%)$ of control had KA (Table 2, Table 3).

The frequencies of these tumors were not related to gender as there was no statistical difference.

Also no patient with photosensitivity or actinic reticuloid was seen among patients with vitiligo whether localized or universal vitiligo.

\section{Discussion}

In all autoimmune diseases, there should be destruction of some specific tissue induced by autoimmune reaction whether humeral or cell mediated that result in specific diseases like pemphigus, vitiligo and alopecia areata. But on the other hand, these enhanced exaggerated immune reactions could be protective for other specific diseases in the same patients and this idea had been recently supported by Sharquie et al. where they found autoimmune diseases like pemphigus and lupus erythematosus are protective against any skin tumors like BCC, SCC and Kaposi's sarcoma and infections like fungal infection warts [6].

This new hypothesis has been confirmed by the observation that patients with vitiligo had high levels of P53 at lesional and peri-lesional area when compared with normal skin [7] [8]. As the P53 is a skin guard against skin cancers, hence this study followed another clued work where skin cancers like BCC and SCC had low levels of P53 when compared with normal healthy controls [9]-[11].

This hypothesis and the observations that had been reported encouraged us to conduct the present study aiming to record the frequency of all benign and malignant skin tumors in patients with vitiligo in their different grades of severity and also to be compared with healthy control individuals. The present work had confirmed that subjects in healthy control had higher frequency of benign and malignant tumors than patients with vitiligo.

Also when comparison was done between localized, generalized and universal vitiligo by Chi Square and Fisher exact test, we observed that the frequency of benign and malignant lesion like BCC, SCC, Kaposi's sarcoma where low in patients with generalized vitiligo when compared with localized and almost nil in universal vitiligo and this supports the observation that generalized and severe vitiligo clean the skin from cell tumors either benign or malignant. 
The absence or the low frequency of skin tumors in severe vitiligo patients does encourage the idea that melanin in the epidermis is not an important protective factor against the development of skin tumors. This is in contrast with patients with albinism where they will have a high frequency of skin tumors such as BCC, SCC and $\mathrm{MM}$ as a result of lacking of melanin in their skin [12].

So the question should be raised, why absence of melanin in patients with vitiligo is not a predisposing factor for skin tumors while its absence is a high risk factor in patients with albinism. It is very difficult to answer this question but we can speculate through two ways of mechanism. First one; patients with vitiligo as a result of autoimmune reaction, there will be circulating factors whether fixed to tissue or in blood that reverse the action of sunlight on the skin. The second way, patients with vitiligo had more defense mechanism through repairing the DNA damage induced by sunlight reaction hence preventing the development of skin tumors. Accordingly, further sophisticated investigations are essential in the field of research to support these observations.

Most of our patients with vitiligo had a long period of outdoor activity but no patient in the present study had history of photosensitivity, although they had absence of melanin. Also it is difficult to find explanation but as mentioned before, those patients with vitiligo especially severe one might have protective factors that initiated by autoimmune reaction.

\section{Conclusion}

Vitiligo as autoimmune disease has protective factors against development of skin tumors and photosensitivity and the absence of melanin of the epidermis is not a risk factor.

\section{Funding}

This study was an independent study and not funded by any drug companies.

\section{References}

[1] Alikhan, A., Felsten, L.M., Daly, M. and Petronic-Rosic, V. (2011) Vitiligo: A Comprehensive Overview Part I. Introduction, Epidemiology, Quality of Life, Diagnosis, Differential Diagnosis, Associations, Histopathology, Etiology, and Work-Up. Journal of the American Academy of Dermatology, 65, 473-491. http://dx.doi.org/10.1016/i.jaad.2010.11.061

[2] Jin, Y., Riccardi, S.L., Gowan, K., Fain, P.R. and Spritz, R.A. (2010) Fine-Mapping of Vitiligo Susceptibility Loci on Chromosomes 7 and 9 and Interactions with NLRP1 (NALP1). Journal of Investigative Dermatology, 130, 774-783. http://dx.doi.org/10.1038/jid.2009.273

[3] Truhan, A.P. (1991) Sun Protection in Childhood. Clinical Pediatrics, 30, 412-421. http://dx.doi.org/10.1177/000992289103000702

[4] Patton, L.L. and Valdez, I.H. (1991) Xerodermapigmentosum: Review and Report of a Case. Oral Surgery, Oral Medicine, Oral Pathology, 71, 297-300. http://dx.doi.org/10.1016/0030-4220(91)90303-T

[5] Liddington, M., Richardson, A.J., Higgins, R.M., Endre, Z.H., Venning, V.A., Murie, J.A. and Morris, P.J. (1989) Skin Cancer in Renal Transplant Recipients. British Journal of Surgery, 76, 1002-1005. http://dx.doi.org/10.1002/bjs.1800761005

[6] Sharquie, K.S., Noaimi, A.A. and Al-Jobori, A.A. (2013) Skin Tumors and Skin Infections in Kidney Transplant Recipients vs. Patients with Pemphigus Vulgaris. International Journal of Dermatology, 2013, 1-6.

[7] Sharquie, K.E., Noaimi, A.A., Bandar, A.R. and Mohsin, S.Y. (2014) Vitiligo: Skin Malignancies and Tumor Suppressive Marker P53. Pigmentary Disorders, 1, 1.

[8] van den Wijngaard, R.M., Aten, J., Scheepmaker, A., Le Poole, I.C. and Tigges, A.J. (2000) Expression and Modulation of Apoptosis Regulatory Molecules in Human Melanocytes: Significance in Vitiligo. British Journal of Dermatology, 143, 573-581. http://dx.doi.org/10.1111/j.1365-2133.2000.03712.X

[9] Bolshakov, S., Walker, C.M. and Strom, S.S. (2003) P53 Mutations in Human Aggressive and Non-Aggressive Basal and Squamous Cell Carcinomas. Clinical Cancer Research, 9, 228.

[10] Kim, M. and Park, H.J.S. (2002) Mutations of the P53 and PTCH Gene in Basal Cell Carcinomas: UV Mutation Signature and Strand Bias. Journal of Dermatological Science, 29, 1-9. http://dx.doi.org/10.1016/S0923-1811(01)00170-0

[11] Wang, S.Q., Setlow, R. and Berwick, M. (2001) Ultraviolet A and Melanoma: A Review. Journal of the American Academy of Dermatology, 44, 837-847. http://dx.doi.org/10.1067/mjd.2001.114594

[12] Lookingbill, D.P., Lookingbill, G.L. and Leppard, B. (1995) Actinic Damage and Skin Cancer in Albinos in Northern 
Tanzania: Findings in 164 Patients Enrolled in an Outreach Skin Care Program. Journal of the American Academy of Dermatology, 32, 653-658.

\section{Submit or recommend next manuscript to SCIRP and we will provide best service for you:}

Accepting pre-submission inquiries through Email, Facebook, LinkedIn, Twitter, etc.

A wide selection of journals (inclusive of 9 subjects, more than 200 journals)

Providing 24-hour high-quality service

User-friendly online submission system

Fair and swift peer-review system

Efficient typesetting and proofreading procedure

Display of the result of downloads and visits, as well as the number of cited articles

Maximum dissemination of your research work

Submit your manuscript at: http://papersubmission.scirp.org/ 